\title{
Diagnosis and Treatment of
}

\section{Adenocarcinomas and Squamous Cell Carcinomas of the Lung}

\author{
PRESENTED BY MILLIE DAS, ${ }^{1}$ MD, and ALISON HOLMES TISCH,${ }^{2}$ MSN, RN, ANP-BC, AOCNP ${ }^{\circledR}$
}

From 'Stanford University and VA Palo Alto Health Care System; 25tanford Cancer Center

Presenters' disclosures of potential conflicts of interest are found at the end of this article.

https://doi.org/10.6004/jadpro.2017.8.3.9

(c) 2017 Harborside Press ${ }^{\circledast}$ $\mathrm{n}$ the treatment of advanced lung cancer, histology still guides treatment selection, and a wealth of new targeted and immunotherapeutic agents is changing the natural history of this challenging malignancy, according to two Stanford University clinicians who described the management of adenocarcinomas and squamous cell carcinomas of the lung at JADPRO Live 2016.

Millie Das, MD, of Stanford University and VA Palo Alto Health Care System, summarized the emerging treatment landscape, and Alison Holmes Tisch, MSN, RN, ANP-BC, AOCNP $^{\circledR}$, of Stanford Cancer Center, described the workup and illustrated the management challenges through case reports. Together, they summarized the key elements in management: involving molecular testing, matching mutations to targeted agents, initiating immunotherapy at the right time and in the right patients, and ameliorating toxicities.

\section{PATIENT PRESENTATION AND WORKUP}

"The diagnosis of lung cancer can be challenging, as symptoms can be vague at first and are often attributed to other illnesses," Ms. Tisch said. Typical local symptoms are cough, dyspnea, hemoptysis, and chest pain. General symptoms often include fatigue and weight loss. Secondary to distant metastasis are bone pain and neurologic symptoms. The rare patient may develop paraneoplastic syndromes.

Initial imaging is often a chest radiograph, but a more complete workup involves chest computed tomography (CT), including the adrenals, a common metastatic site. Positron-emission tomography (PET) and dedicated brain magnetic resonance imaging (MRI) can reveal distant metastases. Since molecular testing requires adequate tissue sampling, most patients undergo bronchoscopy, CT-guided biopsy, or thoracentesis, she said.

"With the biopsy, we are hoping to establish the diagnosis, determine the histologic subtype, and perform molecular testing. Make sure to get a decent-sized cell block. Ideally, we like to do a core biopsy," advised Ms. Tisch.

The first distinction in diagnosis is between small cell $(10 \%-15 \%)$ and non-small cell (85\%-90\%) 
lung cancer (NSCLC). Within NSCLC, adenocarcinoma is most common $(30 \%-40 \%)$, followed by small cell $(20 \%-25 \%)$, with large cell $(10 \%-15 \%)$ and other/mixed types $(3 \%-5 \%)$ being less common (American Cancer Society, 2017). It is important to understand the distinctions between adenocarcinoma and squamous histologies (Table), Dr. Das said.

Molecular testing is now an important part of the workup, based on the understanding of driver mutations and the availability of drugs that target them.

In brief, patients with adenocarcinoma, large cell cancer, and NSCLC not-otherwise-specified should be tested for mutations in the epidermal growth factor receptor $(E G F R)$ and translocations of anaplastic lymphoma kinase $(A L K)$ as part of a broader molecular profiling; if these factors are negative or unknown, patients should be tested for ROS1 rearrangement. Patients with squamous cell tumors are candidates for molecular testing if they are never-smokers or have a mixed histology. $\mathrm{Mu}-$ tations of $E G F R$ are present in about $50 \%$ of neversmokers and in about one-third of light smokers (D’Angelo et al., 2011), according to Dr. Das.

Increasingly, other genes are being evaluated, including KRAS, BRAF, HER2, and RET. "We are increasingly interested in next-generation sequencing to look for other potential targets," Dr. Das said. Although drugs targeting these additional mutations are not yet available, knowledge of the genetic landscape "helps us understand what's driving their cancer, and there may be off-label or clinical trial options for them," Ms. Tisch added.
The recent approval of pembrolizumab (Keytruda), an antibody against PD-1, in the first-line setting adds another testing option at diagnosis. To receive this immune checkpoint inhibitor (for patients lacking targetable mutations), patients must demonstrate $\geq 50 \%$ expression of the programmed cell death ligand 1 (PDL1), Ms. Tisch added.

Rebiopsy at the time of disease progression, especially in patients with mutations, helps determine the mechanisms of resistance and informs decisions regarding second-line options. In some patients, it is possible to do so via "liquid biopsy."

\section{SELECTING CHEMOTHERAPY REGIMEN}

Treatment selection for stage IV NSCLC is based on histologic subtype, mutation status, patient performance status, smoking status, presence of central nervous system (CNS) disease, and receipt of prior systemic therapy in the adjuvant or locally advanced setting. The main drug categories are chemotherapy (choice depends on histologic subtype), targeted agents for patients with mutations (especially EGFR, $A L K$, and ROS1), and immune checkpoint inhibitors (anti-PD-1/PD-L1 and antibodies against cytotoxic T-lymphocyte-associated protein 4 [anti-CTLA-4]).

The standard first-line chemotherapy for stage IV NSCLC is a platinum doublet given for four cycles. The landmark Eastern Cooperative Oncology Group (ECOG) 1594 trial established this as the treatment of choice (Schiller et al., 2002). Overall survival was essentially the same for the four regi-

\begin{tabular}{|lll}
\hline \multicolumn{2}{|c|}{ Table. Distinguishing Between Adenocarcinoma and Squamous Histologies } \\
\hline \% NSCLC & Adenocarcinoma & Squamous \\
Age & $30 \%-40 \%$ & $25 \%-30 \%$ \\
Male/female & Bimodal, with younger subset & Older \\
Location & Female & Male \\
Smoking & Peripheral & Central \\
Therapies contraindicated & Never-smoker subset & Usually smoking-related \\
Biomarker-driven targeted therapy & Yes & Pemetrexed, bevacizumab \\
Improved survival & Yes & No \\
\hline
\end{tabular}

Note. NSCLC = non-small cell lung cancer. Information from Li et al. (2013). 
mens-cisplatin/paclitaxel, cisplatin/gemcitabine, cisplatin/docetaxel, and carboplatin/paclitaxel. But with better tolerability than cisplatin, the doublet of carboplatin/paclitaxel became the standard of care, Dr. Das said.

This study was followed by an important phase III noninferiority trial by Scagliotti et al. (2008), who showed that, for some drugs, histology matters. In the first-line setting, cisplatin/pemetrexed (Alimta) improved survival over cisplatin/gemcitabine in patients with adenocarcinoma or large cell NSCLC, whereas cisplatin/gemcitabine was preferred in patients with squamous cell tumors. In patients with nonsquamous disease, median overall survival was 11.8 months in the pemetrexed arm, vs. 10.4 in the gemcitabine arm, leading to the approval of pemetrexed for advanced-stage disease with nonsquamous histology.

Following this study in patients with nonsquamous histology, ECOG 4599 demonstrated a 2-month survival benefit with the addition of bevacizumab (Avastin) to carboplatin/paclitaxel in the first-line setting (Sandler et al., 2006). The use of bevacizumab remains restricted to the nonsquamous subset, as patients with squamous tumors had excess mortality related to pulmonary hemorrhage.

In squamous histology, nanoparticle albuminbound (nab)-paclitaxel (Abraxane; plus carboplatin) almost doubled the response rate (41\%) over paclitaxel/carboplatin (24\%) in a large front-line trial (Socinski et al., 2012), although overall survival in the entire population (squamous and nonsquamous) was similar (11-12 months). Also in squamous cell patients, necitumumab (Portrazza), a second-generation antibody targeting EGFR, when added to cisplatin/gemcitabine, led to an overall survival benefit of 1.6 months in the phase III SQUIRE front-line trial (Thatcher et al., 2015), leading to this drug's approval.

\section{MAINTENANCE AND}

\section{SECOND-LINE CHEMOTHERAPY}

"A number of studies are evaluating the role of maintenance therapy after patients complete first-line therapy with a platinum doublet," Dr. Das said. There are several options: (1) continuous maintenance, where the patient completes four to six cycles of a platinum doublet (with or without bevacizumab); if the patient achieves at least stable disease, he or she continues to receive one or two of the same agents; (2) switch maintenance, in which the patient with stable disease or response then switches to pemetrexed, docetaxel, or erlotinib (Tarceva; assuming the patient did not receive this drug in the first-line setting); (3) "early" second-line therapy, where drugs are offered that might delay progression; this option might be used, for example, for the patient who could not receive a certain drug in the first-line setting due to disease burden.

"While the data support maintenance, many patients don't want to continue chemotherapy after they are done," acknowledged Dr. Das. "It's not the right thing for all patients."

In the second-line setting, chemotherapy could include the immunoglobulin G (IgG) antibody targeting the vascular endothelial growth factor receptor 2 (VEGFR-2) ramucirumab (Cyramza). In the phase III REVEL trial, the addition of ramucirumab to docetaxel improved overall survival by 1.4 months, leading to its US Food and Drug Administration (FDA) approval in 2015 (Garon et al., 2014).

\section{TARGETED THERAPY}

For patients with advanced NSCLC and driver mutations, first-line treatment includes a targeted agent. Mutations in EGFR occur in $10 \%$ to $15 \%$ of all patients with NSCLC and predict responsiveness to the EGFR tyrosine kinase inhibitors (TKIs) erlotinib, gefitinib (Iressa), and afatinib (Gilotrif). Mutations of EGFR, which occur most often in EGFR exons 18-21, are mostly associated with never-smokers, those with adenocarcinoma histology, females, and persons of Asian ethnicity.

The landmark IPASS trial proved the benefit of an EGFR TKI-gefitinib-in patients with EGFR-mutated cancers (Mok et al., 2009). The LUX-Lung trials evaluated another EGFR TKI, afatinib, showing clear benefit over chemotherapy in EGFR-mutated patients (Sequist et al., 2013, 2014; Wu et al., 2014). Patients with exon 19 deletion had the most pronounced survival benefit with afatinib: 33.3 months vs. 21.1 months for chemotherapy (hazard ratio $[\mathrm{HR}]=0.54 ; p=.002$ ) in LUX-Lung 3 (Sequist et al., 2014). 
"This added to the data we have supporting EGFR TKI treatment for mutation-positive patients in the front-line setting," she said. According to the IMPRESS study of gefitinib (Soria et al., 2015), there is no benefit to continuing an EGFR TKI beyond disease progression.

But as effective as the EGFR TKIs are, they are not curative, as most patients become resistant after about 1 year of treatment. It is now standard to look for resistance mutations (especially EGFR T790M, seen in $60 \%$ of patients) in recurrent tumors, blood, or urine.

"It is important to identify the specific EGFR mutation. There are sensitive mutations, primary resistance mutations, and acquired resistance mutations, especially T790M. For a patient with primary resistance, for example, you might not necessarily offer an EGFR TKI first line," Dr. Das explained. The IMPASS trial showed the detriment of treating non-EGFR-mutated patients with an EGFR TKI (Mok et al., 2009). "This changed the way we practice. In mutation-negative patients, we give platinum doublets upfront," she emphasized.

Identifying the T790M mutation has become especially important now that a third-generation EGFR TKI, osimertinib (Tagrisso), has been shown to be effective in this setting and is now approved. In a study by Jänne et al. (2015), 61\% of T790M-positive patients responded to osimertinib, whereas $21 \%$ of T790M-negative patients responded.

Dr. Das acknowledged that although toxicities with EGFR TKIs are usually mild, the occurrence of acneiform rash and diarrhea require intervention in about $30 \%$ of patients. Proactive management can reduce their severity and maximize treatment outcomes.

\section{ALK AND ROS REARRANGEMENTS}

Rearrangements in the EML4-ALK fusion protein are seen in about $5 \%$ of patients with NSCLC adenocarcinoma. They are most common in younger male patients who are light- or never-smokers, and they are believed to be mutually exclusive of EGFR mutations, according to Dr. Das.

Front-line treatment for $A L K$-positive patients is an ALK inhibitor. In a phase I study, $60.8 \%$ of such patients responded to crizotinib
(Xalkori; Camidge et al., 2012). The clear benefits observed in this study led to a change in practice: to initiate treatment with an ALK inhibitor in these patients. Even more potent is ceritinib (Zykadia), which produced robust responses as well in a phase I study (Shaw et al., 2014a). Its activity is independent of prior ALK-inhibitor therapy, "making this a great option for patients treated with crizotinib upfront who develop resistance," Dr. Das indicated.

The most recently approved ALK inhibitor is alectinib (Alecensa). In two pivotal studies (Ou et al., 2016; Shaw et al., 2016), alectinib produced responses in approximately $50 \%$ of patients, including those with prior chemotherapy and CNS metastases. "Its activity in CNS disease (response rates of $57 \%$ and $75 \%$ ) is higher than we've seen with crizotinib or even ceritinib," she revealed. "Though alectinib's current indication is for crizotinib-refractory patients, there is interest in using it in the front-line setting, especially in patients with significant CNS metastases."

Crizotinib is also a first FDA-approved choice for patients with ROS1 fusions, based on a response rate of $72 \%$ in this population, a median duration of response of 17.6 months, and a median progression-free survival of 19.2 months (Shaw et al., 2014b).

Other genomic targets are emerging in lung cancer, including $B R A F, R E T$ fusion, and $M E T$ exon 14 splice mutation. In early trials, these subsets are responding to dabrafenib (Tafinlar) with and without trametinib (Mekinist), cabozantinib (Cometriq), and cabozantinib plus crizotinib, respectively. "With every day that passes, we are finding more targets, and companies are developing active drugs against them," Dr. Das commented.

\section{IMMUNOTHERAPY}

"The hot new topic in oncology is immunotherapy," Dr. Das said. The PD-1/PD-L1 inhibitors have gained an established role now in NSCLC, with the following approvals:

- Nivolumab (Opdivo; PD-1 inhibitor) for squamous and nonsquamous NSCLC in the second-line setting and beyond. No testing for PD-L1 expression is required, and patients lacking $\mathrm{PD}-\mathrm{L} 1$ expression can receive nivolumab. 
- Pembrolizumab (PD-1 inhibitor) for squamous and nonsquamous NSCLC in both the first-line and second-line settings. In the first-line setting, patients must have $\geq 50 \%$ expression of PD-L1 on the companion diagnostic assay (PD-L1 IHC 22C3 pharmDx test); in the second-line setting, expression of $\mathrm{PD}-\mathrm{L} 1 \geq 1 \%$ is required.

- Atezolizumab (Tecentriq; PD-L1 inhibitor) is approved in the second-line setting; PD$\mathrm{L} 1$ testing is not required, and patients lacking PD-L1 expression can receive the drug.

The approval of nivolumab for patients with squamous cell disease was based on the results of CheckMate 017, which showed a median overall survival of 9.2 months with nivolumab and 6.0 months with docetaxel $(\mathrm{HR}=0.59 ; p<.001)$, in patients progressing after one platinum doublet (Brahmer et al., 2015). In patients with nonsquamous disease, approval was also granted, based on 1-year survival of $51 \%$ with nivolumab vs. $39 \%$ with docetaxel in CheckMate 057 (Borghaei et al., 2015). Recently, the recommendation was made to give nivolumab at a fixed dose of $240 \mathrm{mg}$ intravenously every 2 weeks (rather than $3 \mathrm{mg}$ / $\mathrm{kg})$, Dr. Das said.

In 2015, pembrolizumab was approved for patients with NSLC progressing on a platinum doublet, based on KEYNOTE-001. Although initially approved in the second-line setting for patients with $\geq 50 \%$ PD-L1 expression, the indication was recently revised to allow its use in patients with $\geq 1 \% \mathrm{PD}-\mathrm{L} 1$ expression.

The biggest evolution in this field came with the results of KEYNOTE-024 (Reck et al., 2016). In previously untreated patients with $\geq 50 \% \mathrm{PD}$ L1 expression, median progression-free survival was 10.3 months with pembrolizumab vs. 6.0 months with a platinum doublet $(\mathrm{HR}=0.50 ; p<$ .001 ), and median overall survival at 6 months was $80.2 \%$ vs. $72.4 \%$ ( $\mathrm{HR}=0.60 ; p=.005)$.

"With these exciting results, we got the first approval of a checkpoint inhibitor front line," Dr. Das noted.

The anti-PD-L1 antibody atezolizumab was also recently approved for second-line use and beyond. In the POPLAR trial, median overall survival was 12.6 months with atezolizumab vs. 9.7 months with docetaxel (HR = 0.69; Barlesi et al., 2016).
Dr. Das noted that immune checkpoint inhibitors have a unique toxicity profile, related to autoimmunity, which clinicians must learn to manage. This topic was covered in depth by other speakers at JADPRO Live 2016.

"This is clearly a very exciting time in the treatment of lung cancer, with many recent drug approvals," Dr. Das concluded. "The ultimate goal will be to individualize treatment for patients based on specific biomarkers and genetic alterations, leading to treatments that, hopefully, will improve survival."

\section{Disclosure}

The presenters have no potential conflicts of interest to disclose.

\section{References}

American Cancer Society. (2017). Lung Cancer. Retrieved from http://www.cancer.org/cancer/lungcancer/index

Barlesi, F., Park, K., Ciardiello, F., von Pawel, J., Gadgell, S., Hida, T.,...Rittmeyer, A. (2016). Primary analysis from OAK, a randomized phase III study comparing atezolizumab with docetaxel in 2L/3L NSCLC. Annals of Oncology, 27(suppl 6), LBA44_PR. https://doi.org/10.1093/ annonc/mdw435.43

Borghaei, H., Paz-Ares, L., Horn, L., Spiegel, D. R., Steins, M., Ready, N. E.,...Brahmer, J. R. (2015). Nivolumab versus docetaxel in advanced nonsquamous non-small-cell lung cancer. New England Journal of Medicine, 373, 1627-1639. http://dx.doi.org/10.1056/NEJMoa1507643

Brahmer, J., Reckamp, K. L., Baas, P., Crino, L., Eberhardt, W. E., Poddubskaya, E.,...Spigel, D. R. (2015). Nivolumab versus docetaxel in advanced squamous-cell non-small-cell lung cancer. New England Journal of Medicine, 373(2), 123-135. http://dx.doi.org/10.1056/NEJMoa1504627

Camidge, D. R., Bang, Y. J., Kwak, E. L., Iafrate, A. J., VarellaGarcia, M., Fox, S. B.,...Shaw, A. T. (2012). Activity and safety of crizotinib in patients with ALK-positive nonsmall-cell lung cancer: Updated results from a phase 1 study. Lancet Oncology, 13(10), 1011-1019. http://dx.doi. org/10.1016/S1470-2045(12)70344-3

D’Angelo, S. P., Pietanza, M. C., Johnson, M. L., Riely, G. J., Miller, V. A., Sima, C. S.,...Kris, M. G. (2011). Incidence of EGFR exon 19 deletions and L858R in tumor specimens from men and cigarette smokers with lung adenocarcinomas. Journal of Clinical Oncology, 29(15), 2066-2070. https://dx.doi.org/10.1200\%2FJCO.2010.32.6181

Garon, E. B., Ciuleanu, T. E., Arrieta, O., Prabhash, K., Syrigos, K. N., Goksel, T.,...Perol, M. (2014). Ramucirumab plus docetaxel versus placebo plus docetaxel for secondline treatment of stage IV non-small-cell lung cancer after disease progression on platinum-based therapy (REVEL): A multicentre, double-blind, randomised phase 3 trial. Lancet, 384(9944), 665-673. http://dx.doi. org/10.1016/S0140-6736(14)60845-X

Jänne, P. A., Yang, J. C., Kim, D. W., Planchard, D., Ohe, Y., Ramalingam, S. S.,...Ranson M. (2015). AZD9291 in EGFR 
inhibitor-resistant non-small-cell lung cancer. New England Journal of Medicine, 372(18), 1689-1699. http:// dx.doi.org/10.1056/NEJMoal411817

Li, T., Kung, H. J., Mack, P. C., \& Gandara, D. R. (2013). Genotyping and genomic profiling of non-small-cell lung cancer: Implications for current and future therapies. Journal of Clinical Oncology, 31(8), 1039-1049. http://dx.doi. org/10.1200/JCO.2012.45.3753

Mok, T. S., Wu, Y. L., Thongprasert, S., Yang, C. H., Chu, D. T., Saijo, N.,...Fukuoka, M. (2009). Gefitinib or carboplatin-paclitaxel in pulmonary adenocarcinoma. New England Journal of Medicine, 361(10), 947-957. http://dx.doi. org/10.1056/NEJMoa0810699

Ou, S. H., Ahn, J. S., De Petris, L., Govindan, R., Yang, J. C., Hughes, B.,...Kim, D. W. (2016). Alectinib in crizotinibrefractory ALK-rearranged non-small-cell lung cancer: A phase II global study. Journal of Clinical Oncology, 34(7), 661-668. http://dx.doi.org/10.1200/JCO.2015.63.9443

Reck, M., Rodríguez-Abreu, D., Robinson, A. G., Hui, R., Csöszi, T., Fülöp, A.,...Brahmer, J. R. (2016). Pembrolizumab versus chemotherapy for PD-L1-positive nonsmall-cell lung cancer. New England Journal of Medicine, 375(19), 1823-1833. http://dx.doi.org/10.1056/ NEJMoal606774

Sandler, A., Gray, R., Perry, M. C., Brahmer, J., Schiller, J. H, Dowlati, A.,...Johnson, D. H. (2006). Paclitaxel-carboplatin alone or with bevacizumab for non-small-cell lung cancer. New England Journal of Medicine, 355(24), 25422550. http://dx.doi.org/10.1056/NEJMoa061884

Scagliotti, G. V., Parikh, P., von Pawel, J., Biesma, B., Vansteenkiste, J., Manegold, C.,...Ganrada, D. (2008). Phase III study comparing cisplatin plus gemcitabine with cisplatin plus pemetrexed in chemotherapy-naive patients with advanced non-stage non-small-cell lung cancer. Journal of Clinical Oncology, 26(21), 3543-3551. http://dx.doi. org/10.1200/JCO.2007.15.0375

Schiller, J. H., Harrington, D., Belani, C. P., Langer, C., Sandler, A., Krook, J.,...Johnson, D. H. (2002). Comparison of four chemotherapy regimens for advanced non-small-cell lung cancer. New England Journal of Medicine, 346(2), 92-98. http://dx.doi.org/10.1056/NEJMoa011954

Sequist, L. V., Wu, Y., Schuler, M., O’Byrne, K., Sebastian, M., Popat, S.,...Yang, J. (2014). Overall survival with afatinib versus chemotherapy in patients with advanced nonsmall cell lung cancer harboring common (del19/L858R) epidermal growth factor receptor mutations: Results of LUX-Lung 3 and LUX-Lung 6. International Journal of Radiation Oncology, 90(5 suppl), S5-S6. http://dx.doi. org/10.1016/j.ijrobp.2014.08.030

Sequist, L. V., Yang, J. C., Yamamoto, N., O’Byrne, K., Hirsh, V., Mok, T.,...Schuler, M. (2013). Phase III study of afatinib or cisplatin plus pemetrexed in patients with metastatic lung adenocarcinoma with EGFR mutations. Journal of Clinical Oncology, 31(27), 3327-3334. http://dx.doi. org/10.1200/JCO.2012.44.2806

Shaw, A. T., Gandhi, L., Gadgeel, S., Riely, G. J., Cetnar, J., West, H.,...Ou, S. H. (2016). Alectinib in ALK-positive, crizotinib-resistant, non-small-cell lung cancer: A single-group, multicentre, phase 2 trial. Lancet Oncology, 17(2), 234-242. http://dx.doi.org/10.1016/S14702045(15)00488-X

Shaw, A. T., Kim, D. W., Mehra, R., Tan, D. S., Felip, E., Chow, L. Q.,...Engelman J. A. (2014a). Ceritinib in ALK-rearranged non-small-cell lung cancer. New England Journal of Medicine, 370(13), 1189-1197. http://dx.doi.org/10.1056/NEJMoal311107

Shaw, A. T., Kim, D. W., Nakagawa, K., Seto, T., Crinó, L., Ahn, M. J.,...Jänne, P. A. (2013). Crizotinib versus chemotherapy in advanced ALK-positive lung cancer. New England Journal of Medicine, 368(25), 2385-2394. http://dx.doi. org/10.1056/NEJMoal214886

Shaw, A. T., Ou, S. H., Bang, Y. J., Camidge, D. R., Solomon, B. J., Salgia, R.,...Iafrate A. J. (2014b). Crizotinib in ROS1-rearranged non-small-cell lung cancer. New England Journal of Medicine, 371(21), 1963-1971. https://doi. org/10.1056/NEJMoal406766

Socinski, M. S., Bondarenko, I., Karaseva, N. A., Makhson, A. M., Vynnychenko, I., Okamoto, I.,...Renschler, M. F. (2012). Weekly nab-paclitaxel in combination with carboplatin versus solvent-based paclitaxel plus carboplatin as first-line therapy in patients with advanced nonsmall-cell lung cancer: Final results of a phase III trial. Journal of Clinical Oncology, 30(17), 2055-2062. http:// dx.doi.org/10.1200/JCO.2011.39.5848

Soria, J. C., Felip, E., Cobo, M., Lu, S., Syrigos, K., Lee, K. H.,... Goss, G. D. (2015). Afatinib versus erlotinib as secondline treatment of patients with advanced squamous cell carcinoma of the lung (LUX-Lung 8): An open-label randomised controlled phase 3 trial. Lancet Oncology, 16(8), 897-907. http://dx.doi.org/10.1016/S14702045(15)00006-6

Thatcher, N., Hirsch, F. R., Luft, A. V., Szczesna, A., Ciuleanu, T. E., Dediu, M.,...Socinski, M. A. (2015). Necitumumab plus gemcitabine and cisplatin versus gemcitabine and cisplatin alone as first-line therapy in patients with stage IV squamous non-small-cell lung cancer (SQUIRE): An open-label, randomised, controlled phase 3 trial. Lancet Oncology, 16(7), 763-774. http://dx.doi.org/10.1016/ S1470-2045(15)00021-2

Wu, Y. L., Zhou, C., Hu, C. P., Feng, J., Lu, S., Huang Y,...Geater, S. L. (2014). Afatinib versus cisplatin plus gemcitabine for first-line treatment of Asian patients with advanced non-small-cell lung cancer harbouring EGFR mutations (LUX-Lung 6): An open-label, randomised phase 3 trial. Lancet Oncology, 15(2), 213-222. http://dx.doi. org/10.1016/S1470-2045(13)70604-1 